A REANALYSIS OF THE EFFECT OF THE NEW JERSEY MINIMUM WAGE INCREASE ON THE FAST-FOOD INDUSTRY WITH REPRESENTATIVE PAYROLL DATA

\author{
David Card
}

Alan B. Krueger

Working Paper 6386 


\title{
A REANALYSIS OF THE EFFECT OF THE NEW JERSEY MINIMUM WAGE INCREASE \\ ON THE FAST-FOOD INDUSTRY WITH REPRESENTATIVE PAYROLL DATA
}

\author{
David Card \\ Alan B. Krueger \\ Working Paper 6386 \\ http://www.nber.org/papers/w6386

\section{NATIONAL BUREAU OF ECONOMIC RESEARCH 1050 Massachusetts Avenue \\ Cambridge, MA 02138 \\ January 1998}

The analysis in Sections I and II of this paper is based on confidential Bureau of Labor Statistics (BLS) ES-202 data. The authors thank the BLS staff for assistance with these data. Although the BLS data are confidential, persons employed by an eligible organization may apply to BLS for restricted access to ES-202 data for statistical research purposes. All opinions and analysis in this paper reflect the views of the authors and not the U.S. government or the National Bureau of Economic Research. We thank members of the Princeton Labor Workshop, Larry Katz and David Neumark for helpful comments, and the Princeton University Industrial Relations Section for research support.

(C) 1998 by David Card and Alan B. Krueger. All rights reserved. Short sections of text, not to exceed two paragraphs, may be quoted without explicit permission provided that full credit, including $\odot$ notice, is given to the source. 
A Reanalysis of the Effect of the New Jersey

Minimum Wage Increase on the Fast-Food

Industry with Representative Payroll Data

David Card and Alan B. Krueger

NBER Working Paper No. 6386

January 1998

JEL No. J23

\section{ABSTRACT}

This paper re-examines the effect of the 1992 New Jersey minimum wage increase on employment in the fast-food industry. We begin by analyzing employment trends using a comprehensive new data set derived from the Bureau of Labor Statistics's (BLS's) ES-202 data file. Both a longitudinal sample and a repeated-cross-section sample drawn from these data indicate similar or slightly faster employment growth in New Jersey relative to eastern Pennsylvania after the rise in New Jersey's minimum wage, consistent with the main findings of our earlier survey. We also use the ES-202 data to measure the effects of the 1996 increase in the federal minimum wage, which raised the minimum wage in Pennsylvania but not in New Jersey. We find no indication of relative employment losses in Pennsylvania. In light of these findings, we re-examine employment trends in the sample of fast-food restaurants assembled by the Employment Policies Institute (EPI) and David Neumark and William Wascher. The differences between this sample and both the BLS data and our earlier sample are attributable to a small set of restaurants owned by a single franchisee who provided the original Pennsylvania data for a 1995 EPI study. We also find that employment trends in the EPI/Neumark-Wascher sample are strikingly different for firms that reported their data on a weekly, biweekly or monthly basis, possibly because of seasonal factors. Controlling for the systematic effects of the varying reporting intervals, the combined EPI/Neumark-Wascher sample shows no difference in hours growth between New Jersey and Pennsylvania.

David Card

Department of Economics

549 Evans Hall

University of California

Berkeley, CA 94720

and NBER

card@econ.berkeley.edu
Alan B. Krueger

Robertson Hall

Woodrow Wilson School

Princeton University

Princeton, NJ 08544

and NBER

akrueger@pucc.princeton.edu 


\section{Introduction}

Replication and reanalysis are important endeavors in economics, especially when new findings run counter to conventional wisdom. In their comment on our 1994 American Economic

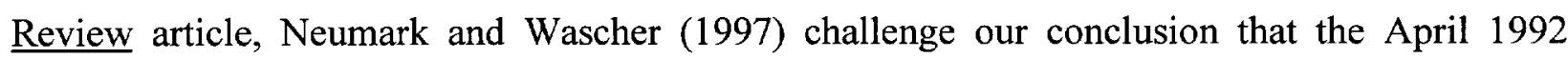
increase in the New Jersey minimum wage led to no loss of employment in the fast-food industry. Using data on a non-randomly selected set of restaurants initially collected for Richard Berman of the Employment Policies Institute (EPI) and later supplemented by their own data collection efforts, Neumark and Wascher (hereafter NW) conclude that "... the New Jersey minimum wage increase led to a relative decline in fast-food employment in New Jersey" compared to Pennsylvania. ${ }^{1}$ They attribute the discrepancies between their findings and ours to problems in our fast-food restaurant data set. Specifically, they argue that our use of employment data derived from telephone surveys, rather than from payroll records, led us to draw faulty inferences about the effect of the New Jersey minimum wage.

In this paper we attempt to reconcile the contrasting findings by analyzing administrative employment data from a new representative sample of fast-food employers in New Jersey and Pennsylvania, and by re-analyzing NW's data. Most importantly, we use the Bureau of Labor Statistics's (BLS's) ES-202 data file to examine employment growth of fast-food restaurants in a set of major chains in New Jersey and nearby counties of Pennsylvania. ${ }^{2}$ We draw two samples from the ES-202 files: a longitudinal file that tracks establishments between 1992 and

\footnotetext{
${ }^{1}$ In the March 1995 version of their paper, NW relied exclusively on 71 observations collected by EPI. Subsequent versions have also included information from their supplemental data collection.

${ }^{2}$ The ES-202 data are also known as the Business Establishment List. Persons employed by an eligible organization may apply to BLS for restricted access to ES-202 data for statistical research purposes.
} 
1993, and a series of repeated cross-sections from the end of 1991 through 1996. Because the BLS data are derived from Unemployment Insurance payroll records, the employment measures are free of the kinds of survey errors that may have affected our earlier results. In addition, because the ES-202 data include information for every covered employer, there is no reason to doubt the representativeness of the BLS sample.

A comparison of fast-food employment growth in New Jersey and Pennsylvania over the period of our original study confirms the main findings in our 1994 paper, and calls into question the representativeness of the sample assembled by Berman, Neumark, and Wascher. Consistent with our original sample, the BLS fast-food data set indicates slightly faster employment growth in New Jersey than in the Pennsylvania border counties over the time period that we initially examined, although in most specifications the difference between New Jersey and Pennsylvania is small and statistically insignificant. We use the BLS data to examine longer-run effects of the New Jersey minimum wage increase, and to conduct a preliminary analysis of the effect of the 1996 increase in the federal minimum wage, which was binding in Pennsylvania but not in New Jersey (where the state minimum wage already exceeded the new federal standard). Our analysis of this new policy intervention is consistent with the conclusion that modest changes in the minimum wage have little systematic effect on employment.

In light of these findings we go on to re-examine the Berman-Neumark-Wascher (BNW) sample and evaluate NW's contention that the rise in the New Jersey minimum wage caused employment to fall in the state's fast-food industry. Our re-analysis leads to three main conclusions. First, the pattern of employment growth in the BNW sample of fast-food restaurants across chains and geographic areas within New Jersey is quite consistent with our original survey 
data. The differences between the BNW sample and ours are attributable to differences in the sample of Pennsylvania restaurants in their data set, which unlike our original sample and the BLS data, show a rise in fast-food employment in the state. Second, the anomalous behavior of the BNW Pennsylvania sample is driven by restaurants owned by one Burger King franchisee, who comprised the entire EPI sample of Pennsylvania franchises. Third, the patterns of employment changes (or more precisely, scaled hours changes) across different restaurants in the BNW sample vary systematically with the period over which the data were reported. In particular, establishments that reported on a bi-weekly basis had faster growth than those that reported on a monthly or weekly basis. The reporting periods may matter because of different seasonal factors in the two waves of the BNW sample (e.g., holidays or weather) or because of imperfect scaling of hours. In any case, a disproportionately high fraction of Pennsylvania restaurants reported their data in bi-weekly intervals, leading to an overstatement of relative employment growth in that state. Once this peculiar feature of the sample is taken into account, the BNW data indicate virtually identical hours growth in New Jersey and eastern Pennsylvania.

Based on all the evidence now available, including the BLS sample, our earlier sample, and the BNW sample, we conclude that the increase in the New Jersey minimum wage in April 1992 had little or no systematic effect on total fast-food employment in the state, although there may have been individual restaurants where employment rose or fell in response to the higher minimum wage. 


\section{Analysis of Representative BLS Fast-Food Restaurant Sample}

\section{A. Description of BLS ES-202 Data}

On April 1, 1992, the New Jersey state minimum wage increased from $\$ 4.25$ to $\$ 5.05$ per hour, while the minimum wage in Pennsylvania remained at $\$ 4.25$. To examine the effect of the New Jersey minimum wage increase using representative payroll data, we applied to the BLS for permission to analyze their ES-202 data. The ES-202 database consists of quarterly employment records reported by employers to their state Employment Security Agencies. The first question on the New Jersey tax form requests the "Number of covered workers employed during the pay period which includes the 12th day of each month." ${ }^{13}$ The BLS maintains these data as part of the Covered Employment and Wages Program. We analyze two types of samples from the ES-202 file: a longitudinal file and a series of repeated cross-sections.

The longitudinal sample consists of restaurants belonging to a set of the largest fast-food chains. ${ }^{4}$ Restaurants in the sampled chains employed 13 percent of all employees in the eating and drinking industry in New Jersey and eastern Pennsylvania in 1992. There is considerable overlap between the restaurants in the BLS sample and those in our original sample. Restaurants in the sampled chains were identified by a name search of the appropriate fields of the ES-202 file. This search was conducted on all establishments in the eating and drinking industry (SIC 5812) in New Jersey and eastern Pennsylvania in the first quarter of 1991, first quarter of 1994, and fourth quarter of 1996. The observations from these quarters were inspected to eliminate

\footnotetext{
${ }^{3}$ The first question on the Pennsylvania form requests the "Total covered employees in pay period incl. 12th of month." Employers are asked to report employment for each month of the quarter. A copy of these forms is available from the authors on request.

${ }^{4}$ For confidentiality reasons, BLS has requested that we not reveal the identity or number of these chains. We can report, however, that there are fewer than 10 chains in the sample.
} 
establishments that were not restaurants in the relevant chains, or to add restaurants that were missed by the algorithm used in the computerized name search. If a restaurant in one of the fastfood chains was discovered that was not identified by the name search, the computer algorithm was amended to include that name.

The original Card-Krueger (CK) sample contained data on restaurants in 7 counties of Pennsylvania (Bucks, Chester, Lackawanna, Lehigh, Luzerne, Montgomery, and Northampton). Because this is a somewhat idiosyncratic group -- with some counties located right on the New Jersey border and others off the border -- we decided to expand the sample to include 7 additional counties: Berks, Carbon, Delaware, Monroe, Philadelphia, Pike, and Wayne. In the results that follow, we present estimates for both our original 7 counties and for the larger set of 14 counties.

Once restaurants in the relevant chains and counties were identified, we merged data on the restaurants for selected months between the first quarter of 1992 and the fourth quarter of 1994. ${ }^{5}$ To mirror the CK sample, only establishments with non-zero employment in February or March of 1992 -- the months covered by Wave 1 of our survey -- were included in the longitudinal analysis file. ${ }^{6}$ The final data set contains 687 establishments. A total of 16 (2.3 percent) of these establishments had zero or missing employment in November or December of 1992, the months covered by Wave 2 of our survey. These establishments either closed or could

\footnotetext{
${ }^{5}$ The ES-202 file also contains data on total quarterly payroll. These data are problematic for our purposes, however, because any income drawn by the franchise owner should be included in this field for incorporated restaurants. Thus, if an increase in workers' earnings is offset by a decline in the income the owner draws, the quarterly payroll data will not reflect the increase in workers' pay.

${ }^{6}$ Additionally, to ensure that the sample consisted exclusively of restaurants (as opposed to, e.g., headquarters or monitoring posts), the authors restricted the sample to establishments with an average of 5 or more employees in February and March 1994, and average monthly payroll per employee below \$3,000 in 1992:Q1 and 1992:Q4. These restrictions eliminated 17 observations from the original sample of 704 observations.
} 
not be tracked because their reporting information changed.

A potential limitation of the BLS longitudinal sample for the present paper should be noted. The ES-202 data pertain to "reporting units" that may be single establishment units or multi-establishment units. The BLS encouraged employers to report their data at the county level or below in the early 1990s. Some employers were in the process of switching to a county-level reporting basis during our sample period. Consequently, some restaurants that remained open were difficult to track because they changed their reporting identifiers. Fortunately, most of the restaurants that were in this situation could be tracked by searching addresses and other characteristics of the stores. All of the restaurants that were not linked to subsequent months' data were assumed closed and assigned zero employment for these months, even though some of these restaurants may not have closed. This is probably a more common occurrence for New Jersey than Pennsylvania: 0.4 percent of the Pennsylvania restaurants had zero or missing employment at the end of 1992, as compared to 3.4 percent of New Jersey restaurants. In our original survey, 1.3 percent of Pennsylvania restaurants and 2.7 percent of New Jersey restaurants were temporarily or permanently closed at the end of $1992 .^{7}$

Also note that because firms are allowed to report on more than one unit in a county in the BLS data, some of the records reflect an aggregation of data for multiple establishments. We address both of these issues in the analysis below. Perhaps more importantly, these problems do not affect the cross-sectional files that we also analyze.

To draw the repeated cross-section file, the same name search algorithm was applied each

\footnotetext{
${ }^{7}$ An interviewer visited all of the non-responding stores in both states to determine if they were closed in our original survey.
} 
quarter between 1991:Q4 and 1996:Q4. ${ }^{8}$ This time period spans the months covered in our original survey. Again, data were selected for the same chains in New Jersey and the 14 counties in eastern Pennsylvania. Every month's data from the sampled quarters was selected. The crosssectional sample probably provides the cleanest estimates of the effect of the minimum wage increase because it incorporates births as well as deaths of restaurants, and because possible problems caused by changes in reporting units over time are minimized.

\section{B. Summary Statistics and Differences in Differences}

Table 1 reports basic employment summary statistics for New Jersey and for the Pennsylvania counties, before and after the April 1992 increase in New Jersey's minimum wage. Panel A is based on the BLS sample of fast-food restaurants. In the first row, the "before" period pertains to average employment in February and March of 1992, and the "after" pertains to average employment in November and December of $1992 .{ }^{9}$ The second row reports employment figures for February and November, which were the most common survey months in our telephone survey. The third row uses data spanning the 12-month period from March 1992 to March 1993. Finally, for comparison, Panel B of Table 1 reports the corresponding employment statistics calculated from the CK survey. ${ }^{10}$

Several conclusions are apparent from the means in Table 1. First, the BLS data indicate

\footnotetext{
${ }^{8}$ Because of a relatively high frequency of imputed employment values prior to 1991:Q4, we do not use data from earlier months.

${ }^{9}$ In one case, employment was zero in March 1992, so the February figure was used.

${ }^{10}$ For comparability with BLS data, we calculate total employment in our survey data by adding together the number of full-time, part-time and managerial workers. This approach differs from Card and Krueger (1994), which weights part-time workers by 0.5 to derive full-time equivalent employment. The original CK data are available via anonymous ftp from the MINIMUM directory of IRS.PRINCETON.EDU.
} 
a slight rise in employment in New Jersey's fast-food restaurants over the period we studied, and a slight decline in employment in Pennsylvania's restaurants over the same period. Our telephone survey data indicate a net gain in New Jersey relative to Pennsylvania of 2.4 workers per restaurant, whereas the BLS data in row 2 indicate a smaller net gain of 1.1 workers between February and November of 1992. Second, between March 1992 and March 1993, the BLS data indicate that both New Jersey and Pennsylvania experienced a decline in average employment, with the decline being larger in Pennsylvania. Third, the average employment level in the BLS data is somewhat greater than the average level in our data, probably because some of the observations in the BLS data pertain to multiple establishments. Fourth, our data and the BLS data indicate that average restaurant size was initially larger in Pennsylvania than in New Jersey. By contrast, the BNW data set indicates that "full-time equivalent employment" was initially greater in New Jersey than in Pennsylvania (see Section III below). Finally, the BLS data indicate that the results for the 7 Pennsylvania counties that we used in our initial sample and the wider set of 14 counties are generally similar.

Neumark and Wascher (1997) and others have emphasized the fact that the dispersion in full-time employment changes in our data set is greater than the dispersion in changes in total hours worked in the BNW data. Interestingly, the BLS data display roughly the same standard deviation of employment changes as was found in our original sample. For example, in New Jersey the standard deviation of the change in employment across reporting units between February and November of 1992 was 10.12 according to the BLS data, which slightly exceeds the standard deviation calculated from our survey data (9.82) over approximately the same months. One problem with this comparison is that some of the BLS reporting units combine 
multi-establishment restaurants that may have broken out over time, whereas our unit of observation was consistently the individual restaurant. To address this issue, we restricted the BLS sample to reporting units that initially had fewer than 40 employees; reporting units this size are almost certainly individual restaurants. The standard deviation of employment changes for this truncated BLS sample is 9.0 for New Jersey and 6.8 for Pennsylvania; these figures compare to 8.0 and 8.8 , respectively, if we likewise truncate our survey data.

More generally, the criticism that our telephone survey was flawed because the employment changes show a high degree of dispersion strikes us as off the mark for three other reasons. First, reporting errors in employment data collected from a telephone survey are not terribly surprising. Dispersion in our data is not out of line from that in other establishment-level employment surveys (e.g., Davis, Haltiwanger, and Schuh, 1996). Second, as long as measurement error in the dependent variable has the same mean in New Jersey and Pennsylvania, estimates based on our data will be unbiased. We know of no reason to suspect that the New Jersey and Pennsylvania managers who responded to our survey would misreport employment data in a systematically different way. Third, the standard deviation of full-time equivalent employment changes is potentially sensitive to the way data on hours, or combinations of parttime and full-time employees, are scaled. NW convert weekly payroll hours data into a measure of employment by dividing by 35 , but a smaller divisor would lead to larger dispersion of employment in their data. The standard deviation of proportionate changes in employment is invariant to scaling and is fairly similar in all three data sets: 0.29 in the BLS data, 0.35 in BNW's data, and 0.39 in our earlier survey data. 


\section{Regression-Adjusted Models}

Panels A and B of Table 2 present basic regression estimates using the BLS ES-202 sample of fast-food restaurants. The models presented in this table essentially parallel the main specifications in Card and Krueger (1994). The dependent variable in the first two columns is the change in the number of employees, and the dependent variable in the last two columns is the proportionate change in the number of employees. ${ }^{11}$ Employment changes are measured between February-March 1992 and November-December 1992. Columns 1 and 3 include as the only regressor a dummy variable indicating whether the restaurant is located in New Jersey or eastern Pennsylvania. These estimates correspond to the difference-in-differences estimates that can be derived from row 1 of Table 1. The models in columns 2 and 4 add a set of additional control variables: dummy variable for the identity of the restaurant chain; and a dummy variable indicating whether the reporting unit was a sub-unit of a multi-unit employer. ${ }^{12}$

The regression results in Panel A of Table 2, which are based on the employment changes for restaurants in same geographic region surveyed in our earlier work, indicate small, positive coefficients on the New Jersey dummy variable. ${ }^{13}$ Each of the estimates is individually statistically insignificant, however. We interpret these estimates as indicating that New Jersey's employment growth in the fast-food industry over this period was essentially the same as it was for the same set of restaurant chains in the seven Pennsylvania counties.

\footnotetext{
"Following Card and Krueger (1994), the denominator of the proportionate change is the average between first and second period employment.

${ }^{12}$ Observations that are not reported as sub-units of multi-unit establishments are either part of a multi-unit reporting firm or the only restaurant owned by a particular reporting unit.

${ }^{13}$ Because, in principle, the BLS sample contains the population of fast-food restaurants in the designated chains, an argument could be made that the OLS standard errors understate the precision of the estimates. Nonetheless, throughout the paper we rely on conventional tests of statistical significance.
} 
In Panel B, regression results are presented using the wider set of 14 Pennsylvania counties as the comparison group. These results also indicate somewhat faster employment growth in New Jersey following the increase in the state's minimum wage. Only in the proportionate change specifications without covariates, however, is the difference in growth rates between New Jersey and Pennsylvania restaurants close to being statistically significant.

For comparison, Panel $\mathrm{C}$ contains the corresponding estimates from our original sample. These estimates differ (slightly) from those reported in our original paper because we now measure employment as the unweighted sum of full-time workers, part-time workers, and managerial workers. The estimates based on our sample are qualitatively similar to those based on the BLS data, with positive coefficients on the New Jersey dummy variable. In addition, in both data sets the inclusion of additional explanatory variables does not add very much to the explanatory power of the model.

\section{Specification Tests}

The BLS data analyzed in Tables 1 and 2 suggest that the New Jersey minimum wage increase had either no effect, or a small positive effect, on fast-food industry employment in New Jersey vis-a-vis eastern Pennsylvania. To probe this finding further, in Table 3 we examine a variety of other specifications and samples. Panel A of the table presents results using our original 7 Pennsylvania counties, and Panel B uses the wider set of 14 counties. In all of the models, we include a full set of chain dummy variables and the sub-unit dummy variable. In addition, we report results for both the change in employment specification (column 1) and the proportionate employment growth specification (column 2). 
For reference, the first row replicates the basic specifications from Table 2. Rows 2 and 3 examine the sensitivity of our results to alternative choices for handling stores with missing employment data in November-December 1992. In the base specification these stores are assigned 0 employment in the second period, which is equivalent to assuming that they all closed. Recall that some of these stores may have actually remained open but changed reporting identifiers. In row 2, we delete from the sample all stores with missing employment data in the second period; this is equivalent to assuming that all of these stores remained open but were randomly missing employment data. Finally, in row 3, we use the imputation codes in the ES-202 database to attempt to distinguish between closed stores (with an imputation code of 9) and those that had missing data for other reasons. In particular, we add back to the sample any restaurant with missing employment data (or those with 0 reported employment) if they were assigned an imputation code indicating a closure. In our opinion, this is the most appropriate sample for measuring the effect of the minimum wage on the set of stores that were in business just before the rise in the minimum. A comparison of the results in rows 2 and 3 with the base specifications indicates that eliminating stores with missing or zero second-period employment, or including such stores only if the imputation code indicated the store was closed, tends to increase the coefficient on the New Jersey dummy variable.

Two of the observations in the sample had employment increases about twice the mean Wave 1 size; the next largest increase was less than the mean size. ${ }^{14}$ These large employment changes may have occurred because one franchisee acquired another outlet, or for other reasons. To probe the impact of these two outliers, they are dropped from the sample in row 4 . The

\footnotetext{
${ }^{14}$ Large negative employment changes are more likely because of restaurant closings.
} 
estimates are not very much affected by these observations, however.

In Card and Krueger (1994) we calculated the proportionate change in employment with average employment over the two periods in the denominator. (This procedure is used by other analysts of employment change data, including Davis, Haltiwanger, and Schuh, 1996). This specification was selected because we thought it would reduce the impact of measurement error in the employment data. We have continued to use that specification so far in this paper. The specification in row 5 , however, measures the proportionate change in employment with the first period employment in the denominator. With this specification, New Jersey's employment growth is slightly lower than that in the 7 county Pennsylvania sample, although employment growth in New Jersey continues to be greater than in Pennsylvania when the 14 county sample is used.

In row 6 we eliminate from the sample restaurants that are located in counties on the New Jersey shore. These counties may have different seasonal demand patterns than the rest of the sample. The results are not very different in this truncated sample, however. Another way to hold seasonal effects constant is to compare employment over the same months. In row 8 we measure employment changes from March 1992 to March 1993. This 12-month change has the added advantage of allowing employers more time to adjust employment. In levels, the faster employment growth in New Jersey is notably larger when 12-month changes are used.

Finally, in row 8 we measure employment changes from February 1992 to November 1992. As mentioned, these are the months when the preponderance of data in our survey was collected. It is probably not surprising that these results are quite similar to the base specification estimates, which use the average February-March 1992 and average November-December 1992 
employment data.

On the whole, we interpret the BLS longitudinal data as indicating that fast-food industry employment growth in New Jersey was about the same, or slightly stronger, than that in Pennsylvania following the increase in New Jersey's minimum wage. It is possible to choose samples and/or specifications in which employment growth was slightly weaker in New Jersey than in Pennsylvania. This is what one would expect if the true difference in employment growth was very close to zero. We doubt, however, that a representative sample of fast-food restaurants would show robust evidence that employment growth was significantly weaker in New Jersey than in eastern Pennsylvania in the months we have studied.

\section{Repeated Cross-Sections from the BLS ES-202 Data}

As described above, we used the quarterly BLS ES-202 data to draw repeated crosssectional data sets for the fast-food chains each month from the end of 1991 through 1996 . With these data, we calculated total employment for New Jersey, for the 7 counties of Pennsylvania used in our original study, and for the broader set of 14 eastern-Pennsylvania counties each month. Figure 1 summarizes the time-series patterns of aggregate employment from these files. For each of the three geographic regions, the figure shows aggregate monthly employment in the fast-food industry relative to their respective February 1992 levels.

The figure reveals a pattern that is consistent with the longitudinal estimates. In particular, between February and November of 1992 -- the main months our survey was conducted -- fast-food employment grew by 3 percent in New Jersey, while it fell by 1 percent in the 7 Pennsylvania counties and fell by 3 percent in the 14 Pennsylvania counties. Although 
it is possible to find some pairs of months surrounding the minimum wage increase over which employment growth in Pennsylvania exceeded that in New Jersey, on whole the figure provides little evidence that Pennsylvania's employment growth exceeded New Jersey's in the few years following the minimum wage increase.

\section{A. The Effect of the 1996 Federal Minimum Wage Increase}

On October 1,1996 the federal minimum wage increased from $\$ 4.25$ per hour to $\$ 4.75$ per hour. This increase was binding in Pennsylvania, but not in New Jersey because New Jersey's $\$ 5.05$ state minimum already exceeded the new federal minimum. Consequently, the same comparison can be conducted in reverse, with New Jersey now serving as a "control group" for Pennsylvania's experience. The results in Figure 1 clearly indicate greater employment growth in Pennsylvania than in New Jersey following the 1996 minimum wage increase. Between December 1995 and December 1996, for example, employment grew by 11 percent in the 14 Pennsylvania counties and 2 percent in New Jersey. In the 7 county Pennsylvania sample employment grew by 16 percent. It is possible that the superior growth in Pennsylvania relative to New Jersey reflects a delayed reaction to the 1992 increase in New Jersey's minimum wage, but we doubt that employment would take so long to adjust in this high-turnover industry. We also doubt that Pennsylvania's strong employment growth was caused by the 1996 increase in the federal minimum wage, but there is certainly no evidence in these data to suggest that the hike in the federal minimum wage caused Pennsylvania restaurants to lower their employment relative to what it otherwise would have been in the absence of the minimum wage increase.

One caveat, however, is that these data might understate New Jersey's employment growth 
because one chain in the sample discontinued reporting on 37 of its New Jersey establishments between the second and third quarter of 1996. These restaurants might have been closed, or they might have been spun off to another enterprise that is not among the fast-food chains in our sample. To gauge the importance of this phenomenon, we can perform the following hypothetical calculation. Suppose these 37 establishments had continued in the sample, with their employment equal to the average size of establishments in this chain as of 1996:Q1. In this counterfactual scenario, New Jersey's employment would have grown by $6.9 \%$ between December 1995 and December 1996 -- still well below Pennsylvania's employment growth rate. Thus, the BLS data provide little support for the view that the 1996 increase in the federal minimum wage adversely impacted employment in fast-food restaurants in Pennsylvania vis-a-vis New Jersey, at least in this short period following the federal minimum wage increase.

\section{A Reanalysis of the Berman-Neumark-Wascher (BNW) Data Set}

\section{A. Genesis of the BNW sample}

The conclusion we draw from the BLS data and our original survey data is qualitatively different from the conclusion NW draw from the data they collected in conjunction with Berman and the EPI. This discrepancy led us to re-analyze the BNW sample, devoting particular attention to the possible non-representative nature of the data. ${ }^{15}$ We suspect that problems in the BNW sample arise because a scientific sampling method was not used in the EPI data collection effort, and because the data were collected three years after the minimum wage increase.

The BNW sample was assembled in several phases. First, Berman (1995) released a

\footnotetext{
${ }^{15}$ The BNW data that we analyze were downloaded from www.econ.msu.edu in November 1997.
} 
report based on 41 restaurants. ${ }^{16}$ This report, which included analysis conducted by David Neumark, made no mention of the methods used to identify the restaurants in the sample. A companion paper by Neumark and Wascher (1995a) reported that the EPI sample contained 71 restaurants and provided some information on the origins of the sample. ${ }^{17}$ Evidently, informal industry contacts were heavily relied on to select these 71 restaurants. We refer to this sample, augmented with information for one New Jersey store that closed during 1992, as the "original Berman sample." The sample contains data for 10 franchisees in the Burger King and Wendy's chains, although all of the Pennsylvania restaurants belong to one Burger King franchisee who apparently supplied EPI with data on his Pennsylvania outlets but not his New Jersey outlets.

Around the time that Berman launched the EPI study, the Wall Street Journal (January 31, 1995, p. 1) reported:

"Lobbyists for small businesses, retailers and big companies huddled Friday at the Washington office of the National Restaurant Association to plot strategy against the Clinton effort to boost the $\$ 4.25$-per-hour minimum wage. ... The group plans to poke holes in a study widely used by proponents to show employment rose in New Jersey fast-food restaurants when the minimum wage was raised there."

In this environment, concerns were raised about the representative character of the data assembled by Berman's organization (e.g., Schmitt, 1995). In their August 1995 paper Neumark and

\footnotetext{
${ }^{16}$ The actual sample size was not reported. We estimate the sample size from Figures 1 and 2 of the report, which display data for a total of 41 restaurants. Berman also referred to these data in a Wall Street Journal op-ed on March 29, 1995.

${ }^{17}$ The description of the data set in the earliest Neumark and Wascher (1995a) paper states, "Contact was made with franchisees identified in the Chain Operator's Guide"; no mention was made of informal contacts. The most recent version of the paper (Neumark and Wascher 1997, Appendix A) states that "... the original EPI sample was drawn partly from franchisees in the Chain Operator's Guide ..., partly from restaurants owned by other franchisees ... that were identified informally, and partly from parent corporations..." A letter explaining the origins of the sample from the Chief Economist of EPI dated October 21, 1995 made no mention of the Chain Operator's Guide. Information in Neumark and Wascher (1997; Table 7) implies that at least half of the franchised restaurants in the Berman/EPI sample were identified through informal contacts.
} 
Washer wrote that "... to avoid conflicts of interest we subsequently took over the data collection effort from EPI, so that the remaining data came from the franchisees or corporations directly to us." During the period from March to August 1995 they added information for 18 additional restaurants owned by franchisees in the original Berman sample, along with information from 7 additional franchisees and one chain. We refer to this sample of 154 restaurants as the NeumarkWascher (NW) sample. Data for 9 other restaurants were apparently collected by EPI after NW took over data collection (see Neumark and Washer $1995 \mathrm{~b}$, footnote 9 ). ${ }^{18}$ We include these 9 restaurants in the pooled BNW sample, but exclude them from the original Berman subsample and from the NW subsample.

Although NW attempted to draw a complete sample of those restaurants not included in the original Berman sample, there are reasons to doubt the representative nature of their data. First, at least one-third of the franchise owners in the NW supplementary sample had previously supplied some data to EPI. Second, and probably more important, NW's letter to franchisees stated that they were collecting data to "re-examine the New Jersey-Pennsylvania minimum wage study" and emphasized that they were working "in conjunction with ... a restaurant-supported lobbying" organization. This lead-in may have affected response patterns for restaurants with different employment trends in New Jersey and Pennsylvania, accounting for the low response rate in their survey.

For whatever reasons the combined BNW sample represents only a fraction of fast-food restaurants in New Jersey and eastern Pennsylvania belonging to the four chains in the sample.

\footnotetext{
${ }^{18}$ The most recent version of NW's data set includes an indicator variable for restaurants collected by EPI. This variable shows a total of 81 restaurants in the EPI sample, representing the 72 restaurants in the original Berman sample and the 9 restaurants which were provided directly to EPI after March 1995.
} 
While we do not have a precise count of the total number of restaurants in the potential sample universe, we can obtain a lower bound estimate from the number of working telephone listings we found in January 1992 for our own fast-food sample. In New Jersey, where the geographic boundaries of the sample frame are unambiguous, we found 364 valid phone numbers, whereas the BNW sample contains 163 restaurants (see Card and Krueger, 1995, Table A.2.1). In eastern Pennsylvania, we found 109 working phone numbers in the 7 counties we surveyed, whereas the BNW sample contains 72 restaurants in as many as 19 counties. ${ }^{19}$ These comparisons suggest that the BNW sample includes fewer than half of the potential universe of restaurants. If the BNW sample were random this would not be a problem. As explained below, however, many features of the sample suggest otherwise. In particular, the Pennsylvania restaurants in the original Berman sample appear to be substantially different from other restaurants in the data set. If restaurants in the original Berman sample are non-representative, their presence biases results based on the combined BNW sample even if the NW subsample is representative. ${ }^{20}$ As it happens, any down-weighting of the original Berman restaurants in the pooled BNW sample substantially weakens the conclusion that employment fell in New Jersey relative to Pennsylvania.

\section{B. Basic Results}

Table 4 shows the basic patterns of fast-food employment in the pooled BNW sample and

\footnotetext{
${ }^{19} \mathrm{BNW}$ 's sample universe covers a broader region of eastern Pennsylvania than ours because BNW define their geographic area based on our three-digit zip codes. These zip codes cover 19 counties, although our sample universe only included restaurants in 7 counties.

${ }^{20}$ Neumark and Wascher note that there are potential concerns with the Berman sample and attempt to address these concerns by analyzing a subsample of restaurants that were listed in the Chain Operator's Guide. This does not adequately address the issue, however, because even within the potential universe of restaurants in the Guide, some restaurants may have been brought into the BNW sample through informal contacts, while others are not included in the sample (possibly because of a lack of informal contacts).
} 
in various subsamples. The first three rows of the table report data on NW's main employment measure, which is based on average payroll hours reported for each restaurant in February and November of 1992. Franchise owners reported their data to EPI and Neumark-Wascher in different time intervals -- weekly, bi-weekly, or monthly -- for up to three "payroll periods" before and after the rise in the minimum wage. NW converted the data (for the maximum number of payroll periods available for each franchisee) into average weekly payroll hours divided by 35 . As shown in row 1 of Table 4, this measure of full-time employment for the pooled BNW sample shows that stores were initially smaller in Pennsylvania than New Jersey, and that during 1992 stores in Pennsylvania expanded while stores in New Jersey contracted slightly. The "difference in differences" of employment growth is shown in the right-most column of the table, and indicates that relative employment fell by 0.85 full-time equivalents in New Jersey from the period just before the rise in the minimum wage to the period 6 months later.

In rows 2 and 3 we compare these relative trends for restaurants in the original Berman sample and in NW's sample. The difference in relative employment growth in the pooled sample is driven by data from the original Berman sample, which shows positive employment growth in both states, but especially strong growth in Pennsylvania. We emphasize that all the Pennsylvania restaurants in the original Berman sample belong to a single Burger King franchisee. ${ }^{21}$ Thus, any conclusion about the growth of average payroll hours in the fast-food industry in New Jersey relative to Pennsylvania hinges on the representativeness of the data for

\footnotetext{
${ }^{21}$ An earlier draft of our paper reported that this franchisee "apparently provided the earliest data to EPI." David Neumark subsequently informed us that no record was kept of the date or order in which the data were provided. Restaurants belonging to this franchisee are the first observations listed in NW's data file, and are identified as belonging to owner number 3 .
} 
this single franchisee.

The final row of Table 4 reports relative trends in an alternative measure of employment available for a subset of restaurants in the pooled BNW sample -- the total number of nonmanagement employees. In contrast to the pattern for total payroll hours, non-management employment rose faster in New Jersey than Pennsylvania. ${ }^{22}$ Taken at face value, these findings suggest that the rise in the New Jersey minimum wage was associated with an increase in employment, and a small decline in hours per worker. ${ }^{23}$ Unfortunately, although one-half of restaurants in the original Berman sample supplied non-management employment data, only 10 percent of restaurants in the NW subsample reported it. Thus, the sample available for studying relative trends in employment is relatively sparse.

\section{Regression Adjusted Models}

The simple comparisons of relative employment growth in Table 4 make no allowances for other sources of variation in employment growth. The effects of controlling for some of these alternative factors are illustrated in Table 5. Each column of the table corresponds to a different regression model fit to the changes in employment observed for restaurants in the pooled BNW sample.

\footnotetext{
${ }^{22}$ Among the subset of stores that reported non-management employment, the difference-in-differences in average payroll hours / 35 is -0.43 , with a standard error of 0.55 . Thus, there is no strong difference between relative payroll hours trends in the pooled BNW sample and among the subset of restaurants that reported non-management employment.

${ }^{23}$ To compare relative changes in hours and employees it is convenient to work with logarithms, so scaling is not an issue. For the sample of 55 observations that reported both numbers of employees and hours, the differencein-differences of log payroll hours is -0.018 ; the difference-in-differences of log management employees is 0.066 ; and the difference-in-differences of log employees minus log hours is 0.084 (t-ratio $=2.28$ ). Thus, the apparent opposite movement in hours and employees is statistically significant for this small sample.
} 
Column 1 presents a model with only a New Jersey dummy: the estimated coefficient corresponds to the simple difference-of-differences reported in row 1 of Table 4 . Column 2 reports a model with only an indicator for observations in the NW subsample. This variable is highly significant (t-ratio over 8 ) and negative, implying that restaurants in the NW subsample had systematically slower employment growth than those in the original Berman sample. The model in column 3 explores the effect of chain and company-ownership controls. These are jointly significant and show considerable differences in average growth rates across chains, with slower growth among Roy Rogers and KFC restaurants than Wendy's or Burger King outlets.

Finally, the model in column 4 includes indicators for whether the restaurant's employment data were derived from bi-weekly or monthly intervals (with weekly data the omitted category). These variables are also highly significant, and suggest that the period over which the data were reported affects measured employment trends. Relative to restaurants that provided weekly data ( 25 percent of the sample), restaurants that provided bi-weekly data experienced faster hours growth between the two waves of the survey, while restaurants that provided monthly data had slower hours growth.

An important lesson from columns 1-4 of Table 5 is that a wide variety of factors affect measured employment growth in the BNW sample. Many of these factors are also highly correlated with the New Jersey dummy. For example, a disproportionately high fraction of New Jersey stores in the pooled sample were obtained by NW. Since the NW subsample has slower growth overall, this correlation might be expected to influence the estimate of relative employment trends in New Jersey. Additionally, the Pennsylvania sample contains none of the slow-growing KFC outlets. Thus, it may be important to control for these other factors when 
attempting to measure the relative trend in New Jersey employment growth.

The models in columns 5-7 include the indicator for New Jersey outlets and various subsets of the other covariates. Notice that the addition of any subset of controls lowers the magnitude of the New Jersey coefficient by 20-90 percent, and also improves the precision of the estimated coefficient by 10-15 percent. None of the estimated New Jersey coefficients are statistically significant at conventional levels once the other controls are included in the model. Simply controlling for an intercept shift between restaurants in the NW subsample and the balance of the pooled data set reduces the size of the estimated New Jersey coefficient by over 50 percent.

The addition of controls indicating the time interval over which the hours data were reported has a particularly strong impact on scaled hours. Even controlling for chain and ownership characteristics, the bi-weekly payroll indicator is highly significant $(t=3.19)$. In the appendix we present further estimation results and a figure illustrating the differences in Wave 1 hours, Wave 2 hours, and hours growth for restaurants that provided data over different time intervals in the BNW sample. ${ }^{24}$ These results suggest that the differences by reporting interval (particularly between restaurants that reported bi-weekly data and other restaurants) are generic, and not an artifact of specific functional form assumptions or outliers. We are unsure of the reasons for the highly significant differences in measured growth rates between restaurants that reported data over different payroll intervals, although it is possible that they reflect differential seasonal factors or mis-scaling of hours. For example, many restaurants are closed on

\footnotetext{
${ }^{24}$ In Appendix Table 1 we also report employment growth models for the subset of Burger King restaurants only. Among these restaurants the situation is similar: the bi-weekly payroll indicator is positive and highly significant $(\mathrm{t}=2.61)$; and controlling for types of payroll data the New Jersey effect is small and statistically insignificant.
} 
Thanksgiving, which may have been more likely to be covered by some November payroll intervals than others; no adjustment to work hours was made to allow for whether stores were closed during holidays. Most importantly, Table 5 indicates that controlling for the type of payroll data has a large effect on the estimated New Jersey relative employment effect, because a much lower fraction of New Jersey restaurants supplied bi-weekly data. Once these differences are taken into account, the employment growth differential between New Jersey and Pennsylvania all but disappear, even in the pooled BNW sample.

\section{Alternative Specifications and Samples}

The results in Tables 4 and 5 suggest that the measured effects of the New Jersey minimum wage differ between the original Berman sample and the subsequent NW sample. Table 6 reports the estimated coefficient on the New Jersey dummy from a variety of alternative models fit to the pooled BNW sample, the NW subsample, and the original Berman sample. Each row of the table corresponds to a different model specification or alternative measure of the dependent variable; each column refers to one of the three indicated samples. For example, the first row reports the estimated New Jersey effect from models that include no other controls: these correspond to the differences-in-differences reported in Table 4.

Row 2 of the table illustrates the influence of the data from the Burger King franchisee who supplied the Pennsylvania observations in the original Berman sample. When the 26 restaurants owned by this franchisee are excluded, the estimated New Jersey effect in the pooled BNW sample becomes positive. ${ }^{25}$ Without this owner's data it is impossible to estimate the

\footnotetext{
${ }^{25}$ This franchisee supplied data on 23 restaurants (all in Pennsylvania) to the original Berman/EPI data collection effort, and on three additional restaurants (all in New Jersey) to NW's later sample.
} 
New Jersey effect in the original Berman sample. In the NW sample, however, the exclusion has a negligible effect.

Rows 3 and 4 of Table 6 show the estimated New Jersey coefficients from specifications that control for chain and company ownership, and these variables plus indicators for the type of payroll data supplied to BNW (bi-weekly, weekly or monthly). As noted, once controls for the payroll period are included, the New Jersey effect falls to essentially zero in the pooled sample. In the original Berman sample, the New Jersey effect switches sign.

In most of their analysis NW utilize an employment measure based on the average scaled hours data taken over varying numbers of payroll periods across restaurants in their sample. (Data are recorded for up to three payroll periods per restaurant in each wave). To check the sensitivity of the results to this choice, we constructed a measure using only the first payroll period for restaurants that reported more than one period. In principle, one would expect this alternative measure to show the same patterns as the averaged data. As illustrated in Panel B (rows 5 and 6) of Table 6, the use of the alternative employment measure leads to results that are qualitatively similar to the averaged data, but uniformly less supportive of NW's conclusion of a negative employment effect in New Jersey. Even in the original Berman sample the use of the simpler hours measure leads to estimates that are well below conventional significance levels.

Finally, Panel C of Table 6 reports estimates from models that use the proportional change in average payroll hours at each restaurant -- rather than the change in the level of average hours -- as the dependent variable. The latter specifications are more appropriate if employment responses to external factors (such as a rise in the minimum wage) are roughly proportional to the scale of each restaurant. Inspection of these results suggests that the signs of the New Jersey 
effects are generally the same as in the corresponding models for the levels of employment, although the coefficients in the proportional change models are relatively less precise.

Our conclusion from the estimates in Table 6 is that most (but not all) of the alternatives show a negative relative employment trend in New Jersey, although the magnitudes of the estimated effects are generally much smaller than the naive difference-in-differences estimate from the pooled BNW sample. The estimated New Jersey effect is most negative in the original Berman sample, although even in this sample the estimated New Jersey effect reverses sign once controls are introduced for the payroll period of the data. In the NW sample or in the pooled sample that excludes data for the Pennsylvania franchisee who supplied Berman's data, the relative employment effects are small in magnitude and uniformly statistically insignificant (t-ratios of 0.7 or less). These patterns highlight the crucial role of the original Berman data in drawing inferences from the BNW sample. Without these informally-collected data (or more precisely, without the observations from the single Burger King franchisee who provided the initial Pennsylvania data) the BNW sample provides little indication that the rise in the New Jersey minimum wage lowered fast-food employment.

\section{E. Consistency of the BNW Sample with the Card-Krueger Sample}

While we have shown that the evidence of a decline in relative New Jersey employment from the BNW sample is not robust, it is nevertheless interesting to ask how the employment patterns in the two data sets compare. The public-use versions of both data sets include only the first three digits of the zip code of each restaurant, rather than full addresses. This limitation necessitates comparisons of employment trends by restaurant chain and "three-digit zip code 
area". $^{26}$

A useful summary of the degree of consistency between the two samples is provided by a bivariate regression of the average employment changes (by chain and zip code area) from one sample on the corresponding changes from the other. In particular, if the employment changes in the BNW sample are taken to be the "true" change for the cell, then one would expect an intercept of 0 and a slope coefficient of 1 from a regression of the observed employment changes in our data on the changes for the same zip code area and chain in the BNW data. ${ }^{27}$ This prediction has to be modified slightly if the employment changes in the BNW sample are "true" but scaled differently than in our survey. In particular, if the ratio of the mean employment level in our survey to the mean employment level in the BNW sample is $\mathrm{k}$, then the expected slope coefficient is $\mathrm{k}$.

Table 7 presents estimation results from regressing employment growth rates by chain and zip-code area from our fast-food sample on the corresponding data from the BNW sample. Although 98 chain-by-zip-code cells are available in our data set, only 48 cells are present in the pooled BNW sample. Column 1 shows results for these cells, while columns 2 and 3 present results separately for chain-by-zip-code areas in New Jersey and Pennsylvania. The data underlying the analysis are also plotted in Figure 2.

Inspection of Figure 2 and the regression results in Table 7 suggests that there is a

\footnotetext{
${ }^{26}$ The first three digits of the postal zip code do not correspond to any conventional geographic entity.

${ }^{27}$ The situation is more complex if the BNW data are treated as a noisy measure of the truth, e.g., because of sampling or nonsampling errors. In particular, let $\lambda_{\mathrm{j}}$ represent the reliability of the observed employment changes (by zip-code and chain) in survey $\mathbf{j}(\mathbf{j}=1,2)$. In this case, if the measurement errors in the two surveys are uncorrelated, the probability limit of the regression coefficient from a linear regression of the employment change in survey 1 on the change in survey 2 is $\lambda_{2}$ (the reliability of the second survey), and the probability limit of the Rsquared is $\lambda_{1} \cdot \lambda_{2}$ (the product of the reliability ratios).
} 
reasonably high degree of consistency between the two data sets: the correlation coefficient is 0.47. The two largest negative outliers are in zip codes containing a high proportion of restaurants from EPI's Pennsylvania sample. In light of this finding, and the concerns raised in Table 6 about the influence of the data from the franchisee who supplied these data, we show a parallel set of models in Panel B of Table 7 that excludes this owner's data from the average changes in the BNW sample.

Looking first at the top panel of the table, the regression coefficient relating the employment changes in the two data sets is 0.78. An F-test for the joint hypothesis that this coefficient is 1 and that the intercept of the regression is 0 has a prob-value of 0.47 . Comparisons of the separate results for New Jersey and Pennsylvania suggest that within New Jersey the two data sets are in closer agreement. Across the relatively small number of Pennsylvania cells the samples are less consistent, although we can only marginally reject the hypothesis of a zero intercept and unit slope. Because we used the same survey methods and interviewer to collect data from New Jersey and Pennsylvania, there is no reason to suspect different measurement error properties in the two states in our sample. A comparison of the results in the bottom panel of the table shows that the exclusion of data from the franchisee who provided EPI's Pennsylvania sample improves the consistency of the two data sets, particularly in Pennsylvania. While not decisive, this comparison suggests that the key differences between the BNW sample and our sample are driven by the data from the single franchisee who supplied the Pennsylvania data for the Berman sample. Together with the other evidence in Tables 4-6, this finding leads us to question the representativeness of the EPI's sample. 


\section{F. Patterns of Employment Changes Within New Jersey}

The main inference we draw from Table 7 is that the employment changes in the BNW and Card-Krueger data sets are reasonably highly correlated, especially within New Jersey. Bigger discrepancies arise between the relatively small subsamples of Pennsylvania restaurants. The consistency of the BNW and CK New Jersey samples is worth emphasizing, since in our original paper we found that comparisons of employment growth within New Jersey (i.e., between restaurants that were initially paying higher and lower wages) led to the same conclusion about the effect of the minimum wage as comparisons between New Jersey and Pennsylvania. As a further check on this conclusion we merged the average "proportionate gap" between the new minimum wage and the Wave 1 starting wage for each of the chain-by-zip-code areas in New Jersey derived from our survey data with the average employment changes for the corresponding cells from the BNW sample. We then regressed the average changes in employment $(\Delta \mathrm{E})$ on the average gap measure (GAP) for the 37 overlapping cells. ${ }^{28}$ The estimated regression equation, with standard errors in parentheses, is:

$$
\Delta \mathrm{E}=-2.00+17.98 \mathrm{GAP} \quad \mathrm{R}^{2}=.09 .
$$

The coefficient on the GAP variable in BNW's data is similar in magnitude to the estimate we obtained using the New Jersey micro data from our survey (13.1 with a standard error of 6.6). Furthermore, if we estimate another cell-level model with BNW's employment data and add dummy variables indicating the restaurant chain, we obtain:

\footnotetext{
${ }^{28}$ At the restaurant level this proportionate gap is defined as the difference between the new minimum wage and the restaurant's starting wage in Wave 1 divided by the starting wage in Wave 1 . (The gap is set to zero if the starting wage is above the new minimum wage.) The GAP measure in our regressions is the weighted average of the restaurant-level proportionate gaps, where the weights are the number of restaurants in the cell.
} 


$$
\Delta \mathrm{E}=0.77+12.00 \mathrm{GAP}+\text { Chain Dummmies } \quad \mathrm{R}^{2}=.78 .
$$

In this model, the coefficient on the GAP variable is slightly smaller than in the bivariate regression, but it has a higher t-ratio. The positive estimated coefficients on the GAP variable indicate that employment rose faster at New Jersey restaurants located in areas that were required to raise their entry wage the most when the minimum wage increased. Thus, the pattern of employment growth rates within BNW's sample of New Jersey restaurants confirms our original finding that the rise in the minimum wage had no adverse effect on employment growth at lower-wage relative to higher-wage restaurants in the state.

\section{Conclusion}

After analyzing BNW's data, NW's data, our original survey data, and most importantly, the BLS ES-202 fast-food establishment data, we reach the following conclusion: The increase in New Jersey's minimum wage probably had no effect on total employment in New Jersey's fastfood industry, and possibly had a small positive effect. We have previously written that, because of frictions in the labor market, a minimum wage increase can be expected to cause some firms to reduce employment and others to raise employment, with these two effects potentially cancelling out if the rise in the minimum wage is modest (Card and Krueger, 1995, esp. pp. 1314). If this view is correct, then it would not be surprising to find some specifications and data definitions that yield a negative impact of the minimum wage on employment. But we doubt that a representative survey of fast-food restaurants in New Jersey and eastern Pennsylvania would show a significant adverse impact of the minimum wage on total employment.

The only data set that indicates a significant decline in employment in New Jersey relative 
to Pennsylvania is the small, non-random group of restaurants collected by Berman and EPI. Results of this data set stand in contrast to our survey data, to the BLS's payroll data, and to the supplemental data collected by Neumark and Wascher. The difference between the New JerseyPennsylvania comparison in our original survey and BNW's data cannot be reconciled by inherent differences between a telephone survey and administrative payroll records because the BLS ES-202 data are based on administrative payroll records. Instead, we suspect the common denominator is that representative surveys indicate statistically insignificant and small differences in employment growth between New Jersey and eastern Pennsylvania, while the nonrepresentative data informally collected for Berman produce anomalous results.

An alternative interpretation of the full spectrum of results is that the New Jersey minimum wage increase did not reduce total employment, but it did reduce the average number of hours worked per employee. Neumark and Wascher (1997) reject this interpretation. Although we are less quick to rule out this possibility, we are agnostic about any conclusion concerning average hours worked per employee that relies so heavily on the informally-collected Berman/EPI sample, and the exclusion of controls for the length of the reporting interval. Moreover, within New Jersey the BNW data indicate that hours grew more at restaurants in the lowest wage areas of the state, where the minimum wage increase was more likely to be a binding constraint. This finding runs counter to the view that total hours declined in response to the New Jersey minimum wage increase. 


\section{References}

Berman, Richard, Executive Summary, "The Crippling Flaws in the New Jersey Fast-Food Study," mimeo., Employment Policies Institute, Washington, D.C., March 1995.

Card, David and Alan B. Krueger. Myth and Measurement: The New Economics of the Minimum Wage (Princeton, NJ: Princeton University Press, 1995).

and , "Minimum Wages and Employment: A Case Study of the Fast-Food

$\overline{\text { Industry }}$ in New Jersey and Pennsylvania," American Economic Review, 84, no. 4, September 1994, pp. 772-84.

Davis, Steven, John Haltiwanger, and Scott Schuh. Job Creation and Destruction.

Cambridge, MA: MIT Press, 1996.

Neumark, David and William Wascher, "The New Jersey-Pennsylvania Minimum Wage Experiment: A Re-Evaluation Using Payroll Records," mimeo, Michigan State University, March 1995a, August 1995b, March 1997.

Schmitt, John, "Cooked to Order." The American Prospect, May-June 1995, pp. 82-85. 

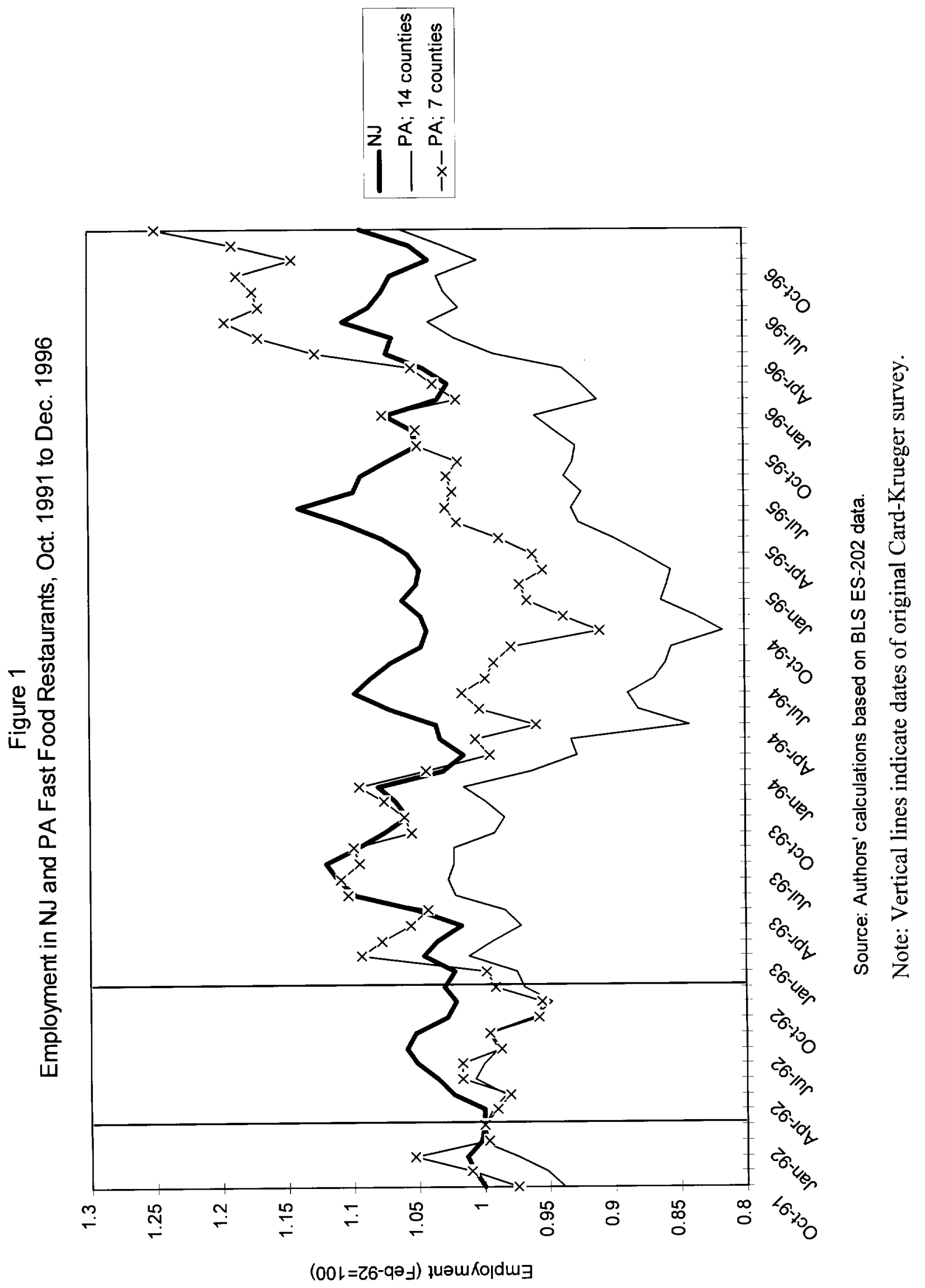

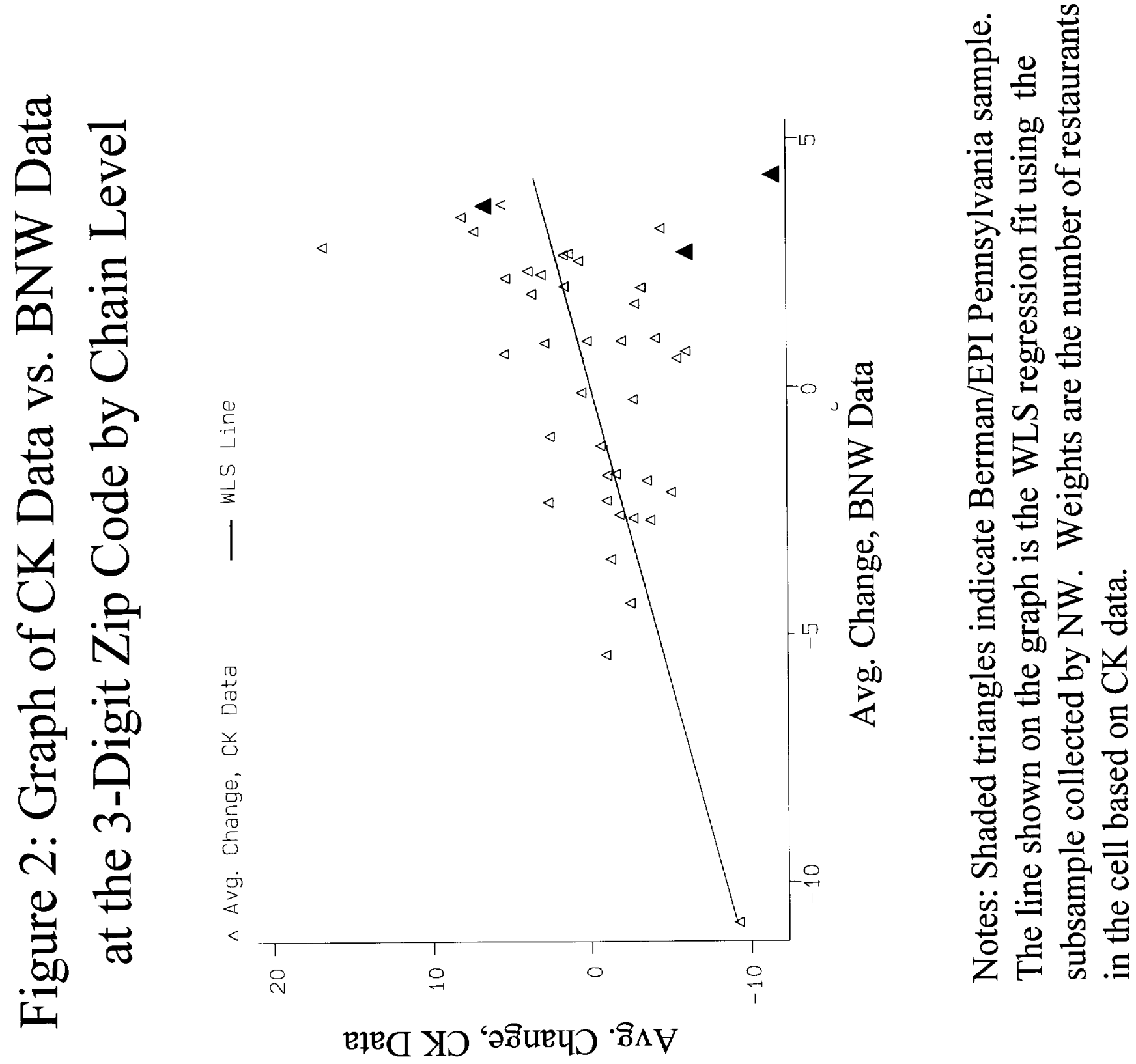


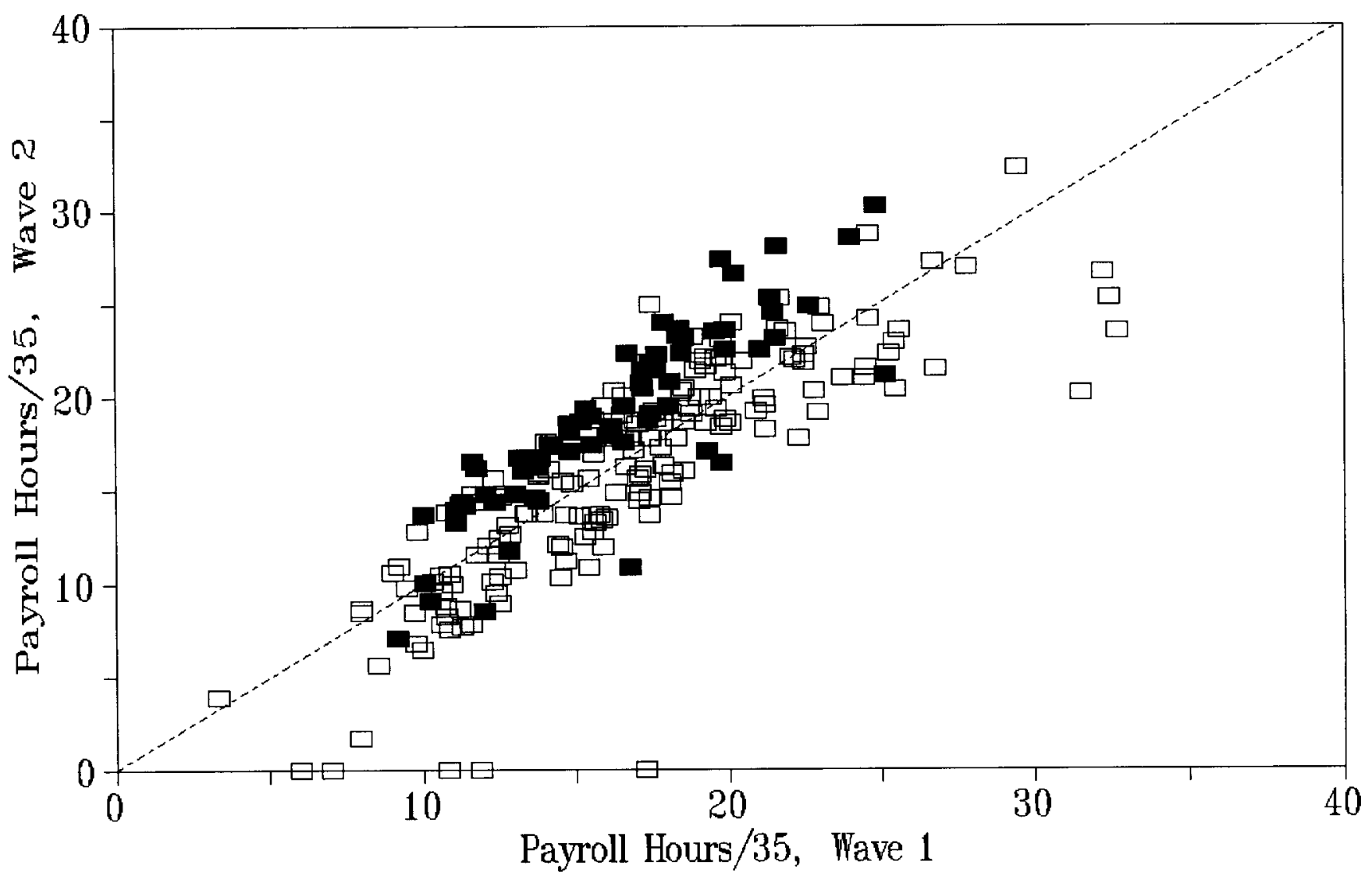

- Biweekly Payroll $\square$ Others

Appendix Figure: Hours in Wave 2 versus Wave 1, by Type of BNW Payroll Data 


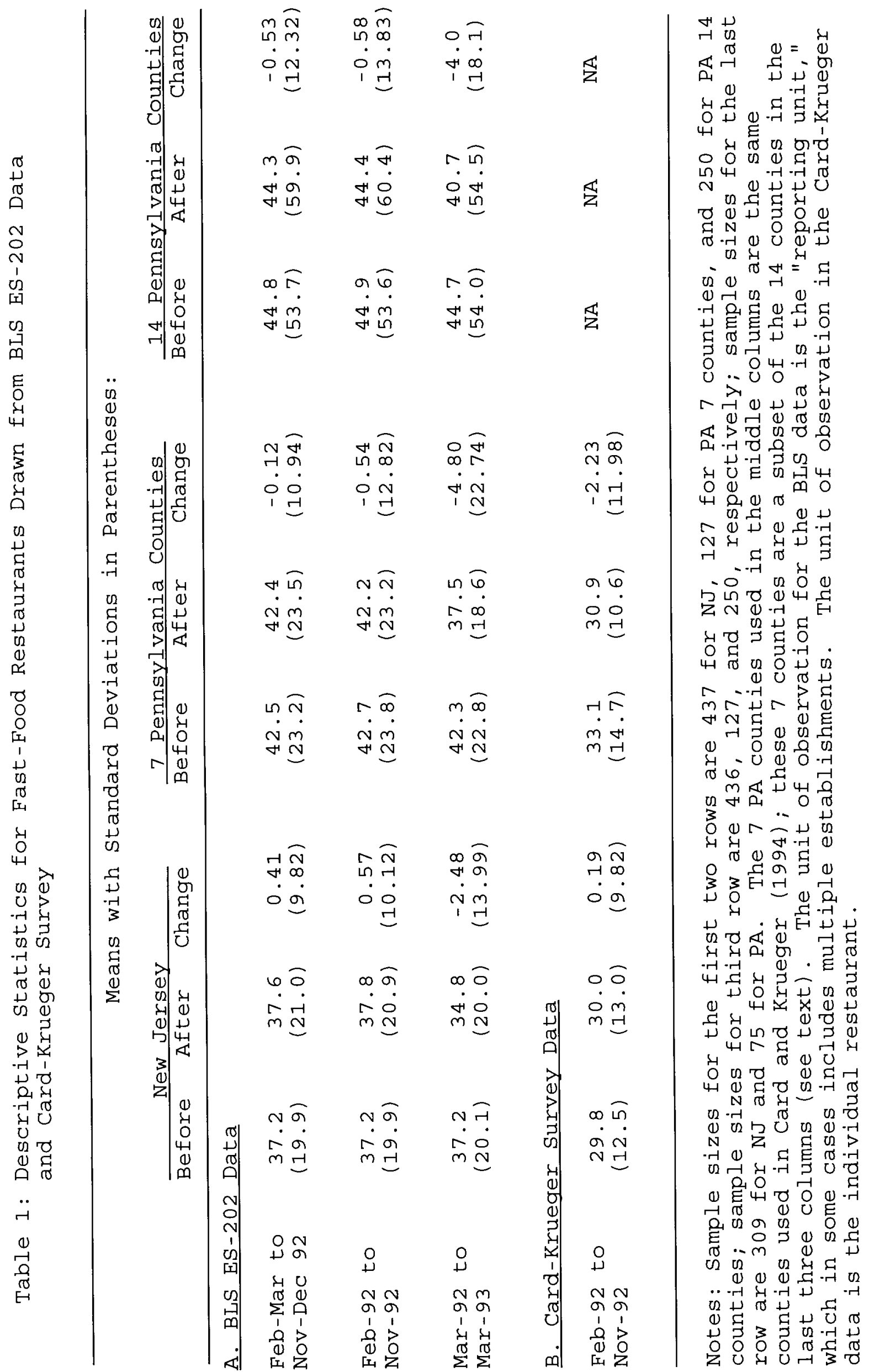


Table 2: Basic Regression Results; BLS ES-202 Fast-Food Data and Card-Krueger Survey Data

\begin{tabular}{lcccc} 
& \multicolumn{3}{c}{ Dependent Variable: } \\
Explanatory & Change in Levels & Proportionate Change \\
Variables & (1) & (2) & & (3)
\end{tabular}

\section{Panel A: All of NJ and 7 Pennsylvania Counties, BLS Data}

$\begin{array}{lcccc}\text { NJ Indicator } & 0.536 & 0.225 & 0.007 & 0.009 \\ & (1.017) & (1.029) & (0.029) & (0.029) \\ \begin{array}{l}\text { Chain Dummies } \\ \text { and Sub-unit } \\ \text { Dummy Var. }\end{array} & \text { No } & \text { Yes } & \text { No } & \text { Yes } \\ \text { Reg. Std. Error } & 10.09 & 9.99 & 0.286 & 0.281 \\ \text { R-Squared } & 0.001 & 0.029 & 0.000 & 0.046\end{array}$

\section{Panel B: All of NJ and 14 Pennsylvania Counties, BLS Data}

$\begin{array}{lcccc}\text { NJ Indicator } & 0.946 & 0.272 & 0.045 & 0.032 \\ & (0.856) & (0.859) & (0.024) & (0.024) \\ \begin{array}{l}\text { Chain Dummies } \\ \text { and Sub-unit } \\ \begin{array}{l}\text { Dummy Var. } \\ \text { Reg. Std. Error }\end{array}\end{array} & \text { No } & \text { Yes } & \text { No } & \text { Yes } \\ \text { R-Squared } & 10.80 & 10.63 & & \\ & 0.002 & 0.042 & 0.303 & 0.294 \\ & & & 0.005 & 0.071\end{array}$

\section{Panel C: Original Card-Krueger Survey Data}

$\begin{array}{lcccc}\text { NJ Indicator } & 2.411 & 2.488 & 0.029 & 0.030 \\ & (1.323) & (1.323) & (0.050) & (0.049) \\ \begin{array}{l}\text { Chain and Co. } \\ \text { Ownership Dummies }\end{array} & \text { No } & \text { Yes } & \text { No } & \text { Yes } \\ \text { Reg. Std. Error } & 10.28 & 10.25 & 0.385 & 0.382 \\ \text { R-Squared } & 0.009 & 0.025 & 0.001 & 0.024\end{array}$

Notes: Each regression also includes a constant. Sample size is 564 for panel A, 687 for panel B, and 384 for panel C. Sub-unit dummy variable equals one if the reporting unit is a sub-unit of a multi-unit employer. For comparability with the BLS data, employment in the CK sample is measured by the total number of full- and part-time employees. Standard errors in parentheses. 
Table 3

Sensitivity of New Jersey Employment Growth Differential to Specification Changes;

BLS ES-202 Fast-Food Restaurant Sample

Specification and

Sample
Change in Levels

(1)
Proportionate Change

(2)
Sample

Size

Panel A: NJ and 7 PA Counties

1. Basic Specification

0.225

(1.029)

Stores

3. Excluding Closed

Stores Unless

Imputation Code $=9$

4. Drop Large Outliers

5. Proportionate Change with

Initial Employment In Base

6. Excluding New Jersey

Shore

7. March 1992 to March 1993

Employment Change

8. February 1992 to November 1992 Employment Change
0.909

$(0.950)$

0.640

$(0.973)$

0.251

$(0.970)$

(0.028)

0.022

$(0.025)$

$(0.024)$

--0.001
-
$(0.032)$

0.032

(1.092)

2.345

(0.035)

1.048

(1.104)
0.009

0.031

0.008

$(0.030)$

0.007

564

549

553

563

564

480

563

0.013

564

- Continued - 
Table 3: Continued

Specification and

Change in Levels

(1)

Proportionate Change

(2)

Sample

Size

Panel B: NJ and 14 PA Counties
1. Basic Specification
0.272
0.032
687
(1.029)
(0.024)
2. Excluding Closed
0.639
0.055
671
Stores
(0.776)
(0.021)
0.338
0.044
675
3. Excluding Closed
(0.787)
$(0.021)$
Imputation $\operatorname{Code}=9$
4. Drop Large Outliers
0.722
0.032
685
$(0.784)$
$(0.023)$
5. Proportionate Change with

$\begin{array}{ll}-- & 0.020\end{array}$
687
Initial Employment In Base
(0.024)
0.069
0.030
603
6. Excluding New Jersey
(0.924)
$(0.025)$
Shore
1.196
0.009
686
7. March 1992 to March 1993
(1.258)
(0.027)
Employment Change
0.624
0.027
687
8. February 1992 to November
(0.927)
$(0.024)$

Notes: The table reports the coefficient (with standard error in parentheses) for the New Jersey dummy variable from a regression of the change in employment (column 1) or proportionate change in employment (column 2) on a New Jersey dummy variable, chain dummy variables, a dummy variable indicating whether the restaurant is reported as a sub-unit of a multiestablishment employer, and a constant. 


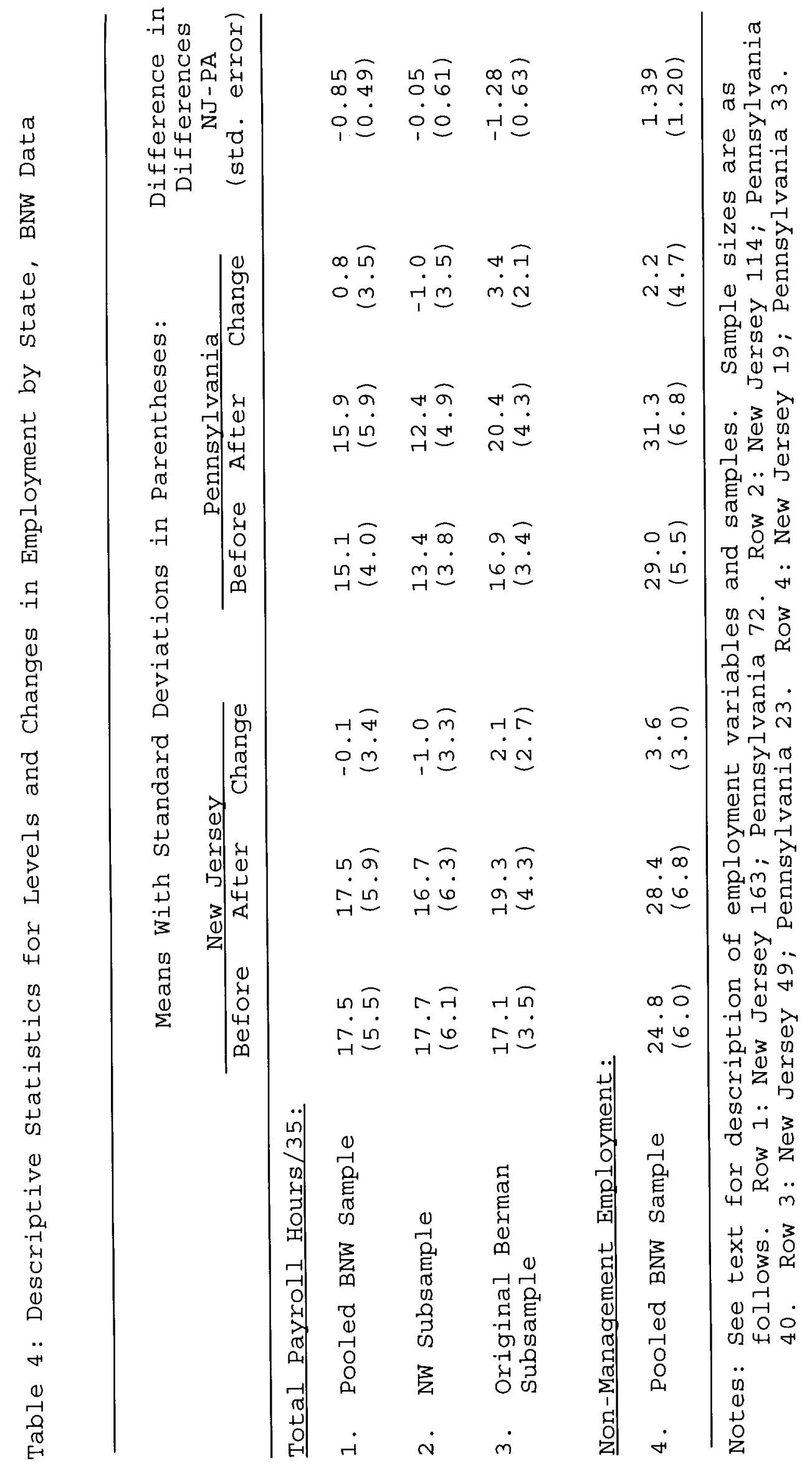




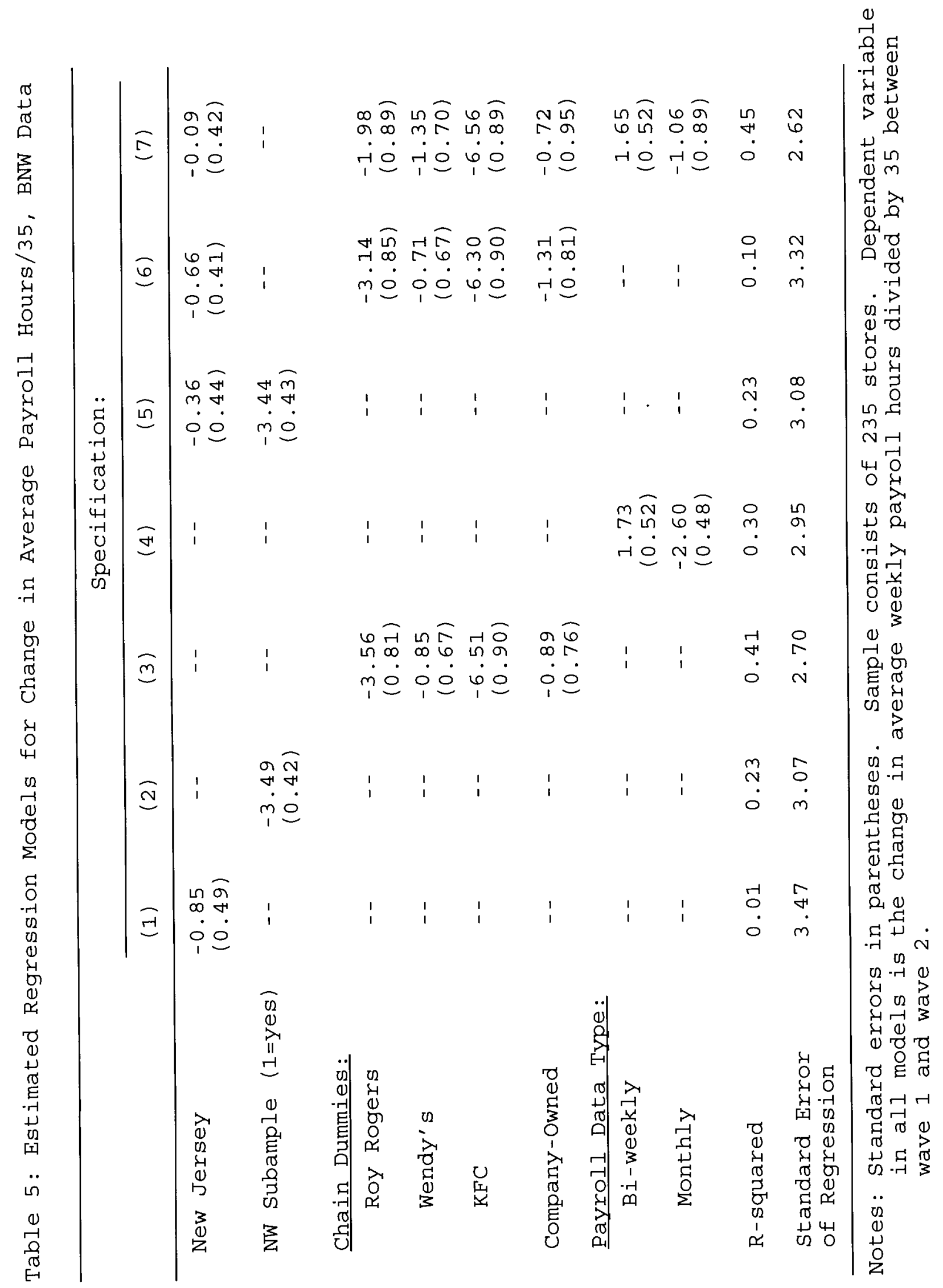


Table 6: Estimated Relative Employment Effects in New Jersey for Alternative Samples and Specifications, BNW Data

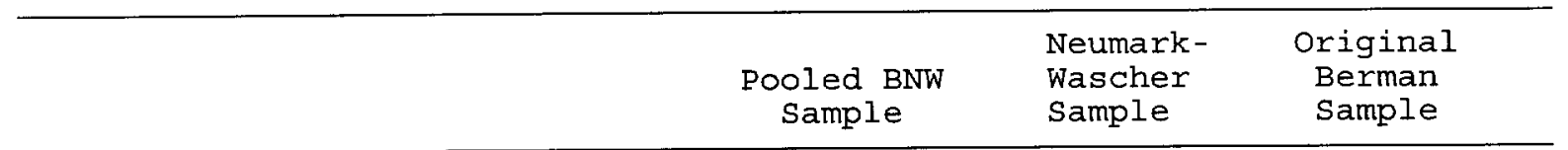

A. Change in Average Payroll Hours/35
1. No Controls
-0.85
$(0.49)$
$-0.05$
$-1.28$
2. Exclude First PA Franchisee,
0.37
$(0.56)$
$(0.61)$
$(0.63)$ No Controls
-0.66
$(0.41)$
$-0.11$
$(0.62)$
3. Controls for Chain and
$-0.27$
$(0.53)$
$-0.95$ Ownership
$-0.09$
$(0.42)$
$-0.22$
$(0.64)$
4. Controls for Chain, Ownership
and Payroll Period
$(0.54)$
0.58
$(0.72)$

B. Change in Payroll Hours/35 Using First Pay Period per Restaurant
5. No Controls
-0.55
$(0.50)$
0.18
$-0.85$
$(0.63)$
$(0.67)$
6. Controls for Chain, Ownership
0.07
$-0.15$
0.96 and Payroll period
$(0.43)$
$(0.52)$
$(0.78)$

\section{Proportional Change in Average Payroll Hours/35}
7. No Controls
$-0.06$
-0.00
$(0.07)$
$-0.09$
$(0.05)$
$-0.03$ 8. Controls for Chain and
Ownership
-0.05
$(0.05)$
$(0.07)$
$-0.04$
$-0.01$
$(0.05)$
$-0.03$
$(0.07)$
9. Controls for Chain, Ownership and Payroll period
$(0.07)$
$-0.08$
(0.08)

Notes: Pooled BNW sample has 235 observations; NW sample has 154 observations; original Berman sample has 71 observations. In row 2, data for 26 restaurants owned by one franchisee are excluded. In this row only, pooled BNW sample has 209 observations; and NW sample has 151 observations. Dependent variable in panel $A$ is the change in average payroll hours between the first and second waves, divided by 35. Dependent variable in panel $B$ is the change in payroll hours for the first payroll period reported by each store between the first and second waves, divided by 35 . Dependent variable in panel $C$ is the change in average payroll hours between the first and second waves, divided by average payroll hours in the first and second waves. standard errors in parentheses. 
Table 7: Comparisons of Employment Growth by Chain and Zip-code Area, CardKrueger data versus Berman-Neumark-Wascher Data

\begin{tabular}{|c|c|c|c|}
\hline & $\mathrm{NJ}$ and $\mathrm{PA}$ & NJ only & PA Only \\
\hline \multicolumn{4}{|l|}{ A. Using Combined BNW Sample } \\
\hline Intercept & $\begin{array}{l}-0.32 \\
(0.56)\end{array}$ & $\begin{array}{c}0.41 \\
(0.50)\end{array}$ & $\begin{array}{l}-3.91 \\
(1.77)\end{array}$ \\
\hline $\begin{array}{l}\text { Change in Employment in BNW } \\
\text { Sample }\end{array}$ & $\begin{array}{c}0.78 \\
(0.22)\end{array}$ & $\begin{array}{l}0.90 \\
(0.19)\end{array}$ & $\begin{array}{c}0.65 \\
(0.68)\end{array}$ \\
\hline R-squared & 0.22 & 0.38 & 0.09 \\
\hline Standard Error & 8.97 & 7.35 & 10.76 \\
\hline $\begin{array}{l}\text { P-value: intercept }=0 \\
\text { slope }=1\end{array}$ & 0.47 & 0.65 & 0.07 \\
\hline $\begin{array}{l}\text { Number of Observations } \\
\text { (Chain } \times \text { Zip-code Cells) }\end{array}$ & 48 & 37 & 11 \\
\hline B. Using Combined BNW Sample & luding Data & n One Fra & \\
\hline Intercept & $\begin{array}{l}-0.26 \\
(0.54)\end{array}$ & $\begin{array}{l}0.36 \\
(0.51)\end{array}$ & $\begin{array}{l}-3.52 \\
(1.67)\end{array}$ \\
\hline $\begin{array}{l}\text { Change in Employment in BNW } \\
\text { Sample }\end{array}$ & $\begin{array}{l}0.87 \\
(0.21)\end{array}$ & $\begin{array}{c}0.91 \\
(0.20)\end{array}$ & $\begin{array}{l}0.93 \\
(0.73)\end{array}$ \\
\hline R-squared & 0.28 & 0.39 & 0.17 \\
\hline Standard Error & 8.56 & 7.40 & 10.27 \\
\hline $\begin{array}{l}\text { P-value: intercept }=0 \\
\text { slope }=1\end{array}$ & 0.71 & 0.72 & 0.14 \\
\hline $\begin{array}{l}\text { Number of Observations } \\
\text { (Chain } \times \text { zip-code Cells) }\end{array}$ & 46 & 36 & 10 \\
\hline
\end{tabular}

Notes: Dependent variable in all models is the mean change in full-time employment for fast-food restaurants of a specific chain in in a specific 3-digit zip code area, taken from the Card-Krueger data set. Independent variable is the mean change in payroll hours divided by 35 for fast-food restaurants (in the same chain and zip code area) taken from the BNW data set. In panel B. restaurants in the BNW sample obtained from the franchisee who provided Berman's Pennsylvania data are deleted prior to forming average employment changes by chain and zip code area. All models are fit by weighted least squares using as a weight the number of observations in the chain-by-zip-code cell in the cardKrueger data set. standard errors in parentheses. 


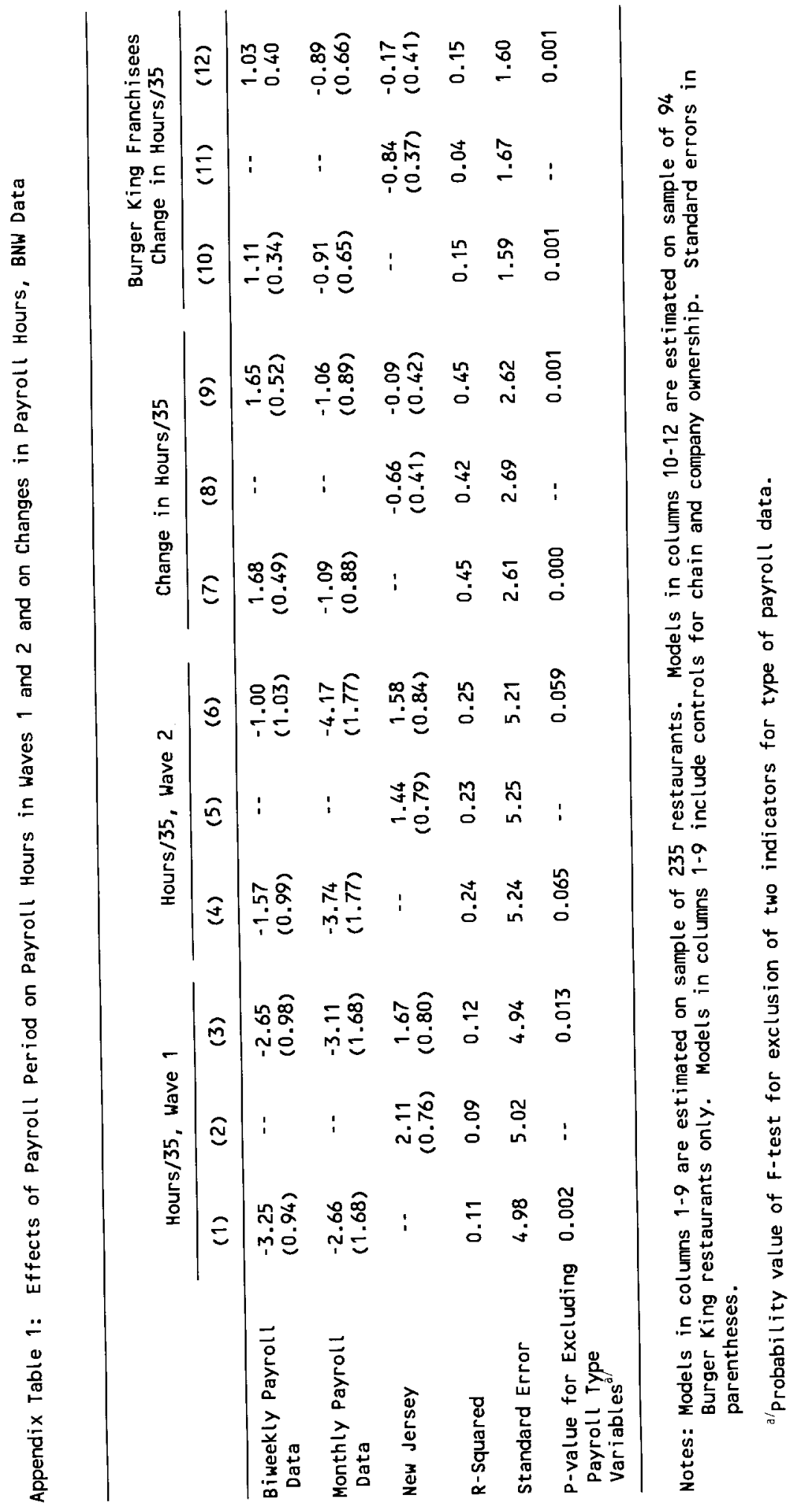

